\title{
Early prediction of cerebral-cardiac syndrome after ischemic stroke: the PANSCAN scale
}

Lian Haijuan ${ }^{1,2,3+}$, Xu Xiaomeng ${ }^{4 \dagger}$, Shen Xuhui ${ }^{3}$, Chen Jinhua ${ }^{2}$, Mao Dandan $^{3}$, Zhao Yan $^{3}$ and Yao Meiqi ${ }^{2^{*}}$

\begin{abstract}
Background: Cerebral-cardiac syndrome, newly developed cardiac damage manifestations subsequent to cerebral injuries, is a common complication of stroke and leads to increased morbidity and mortality. The current study is aimed to develop a risk prediction scale to stratify high-risk population of CCS among ischemic stroke patients.

Methods: The study included 410 cases from four tertiary medical centers from June 2018 to April 2019. The risk prediction model was established via logistic regression from the derivation cohort including 250 cases admitted between June 2018 and December 2018. Another 160 cases admitted from January 2019 to April 2019 were included as the validation cohort for external validation. The performance of the model was determined by the area under curve of the receiver operating characteristic curve. A rating scale was developed based on the magnitude of the logistic regression coefficient.
\end{abstract}

Results: The prevalence of CCS was $55.2 \%$ in our study. The predictive model derived from the derivation cohort showed good calibration by Hosmer-Lemeshow test $(P=0.492)$, and showed sensitivity of 0.935 , specificity of 0.720 , and Youden index of 0.655 . The C-statistic for derivation and validation cohort were 0.888 and 0.813 , respectively. Our PANSCAN score (0 to 10 points) was then established, which consists of the following independent risk factors: PT(12 s-14 s = 0; otherwise = 1), APTT(30s-45s = 0, otherwise = 1), Neutrophils $(50-70 \%=0$; otherwise $=1$ ), Sex $($ female $=1)$, Carotid artery stenosis (normal or mild $=0$; moderate to severe $=2$ ), Age $(\geq 65$ years $=1$ ), NIHSS score $(1$ to $4=2 ; \geq 5=3)$. Patients scored 3 or more points were stratified as high risk.

Conclusion: The risk prediction model showed satisfactory prediction effects. The PANSCAN scale provides convenient reference for preventative treatment and early management for high-risk patients.

Trial registration: The study was retrospectively registered in Chinese Trial Registry. The date of registration is April 17, 2019. Trial registration number: ChiCTR1900022587.

Keywords: Stroke, Cerebral cardiac syndrome, Risk prediction model

\footnotetext{
* Correspondence: zrhlyj@zju.edu.cn; yaomeiqi@163.com

${ }^{\dagger}$ Lian Haijuan and Xu Xiaomeng contributed equally to this work.

${ }^{2}$ The Second Affiliated Hospital, School of Medicine, Zhejiang University, 88 Jiefang Road, Hangzhou 310009, China

Full list of author information is available at the end of the article
}

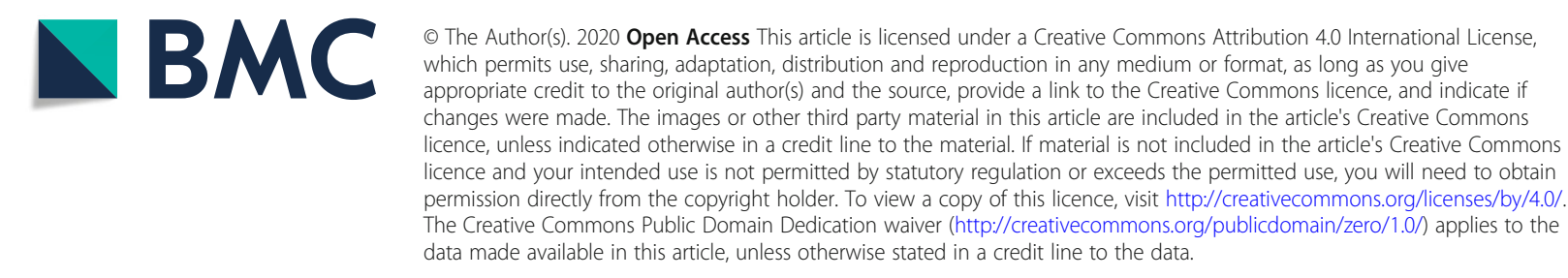




\section{Background}

The interaction between the brain and the heart was recognized as early as the 1940s, when Byer and colleagues first reported abnormal electrocardiography (ECG) findings in six patients with heterogenous acute cerebral diseases including hypertensive encephalopathy and cerebrovascular disease (CVD) in 1947 [1]. Later on, abnormal ECG patterns in CVD were concluded by George Brunch and colleagues in 17 patients diagnosed with acute cerebrovascular accidents, among which 14 were hemorrhagic cases diagnosed by lumbar puncture, and three were unclassified cerebrovascular accident due to technique limitation at that time [2].

In the modern age, with decades of progress in medical science and technology, accumulating evidence further acknowledges the significance of brain-heart connection, which is now referred to as neurocardiology, [3] and the cardiac dysfunctions secondary to cerebral injury is now named as brain-heart syndrome or cerebral cardiac syndrome (CCS) $[3,4]$. As previous study suggested that CCS was more common in CVD patients than in other neurological diseases, [5] recent studies further showed that CCS can occurred in 25-75\% stroke patients, depending on different study design and examine methods [3, 6, 7]. CCS significantly affects prognosis, morbidity and mortality of stroke, and accounts for the second leading cause of death after cerebrovascular disease [3]. In one of the most severe cases, CVD will be complicated with acute myocardial infarction, which has no clear recommendation for ideal management while has an reported incidence of $0.52 \%$ within $24 \mathrm{~h}$ after CVD and $12.7 \%$ among geriatric patients within $72 \mathrm{~h}$ [8]. Therefore, the early detection and management of CCS is particularly important. However, despite the accumulating evidence from domestic and international studies, the underlying mechanism and pathogenesis of CCS are not fully understood and the risk factors for CCS are still controversial. In order to facilitate early stratification of high-risk CCS patients, our study was aimed to detect possible risk factors and to establish a predictive model for clinical practice.

The current study is aimed to identify potential risk factors for CCS after ischemic stroke, so patients with history of previous heart disease were excluded from the study to avoid confounders, and cardioembolic stroke was therefore excluded as well. As a result, the study is focused on the identification of independent predictors of CCS subsequent to non-cardiogenic ischemic stroke and the establishment of a risk prediction scale to stratify high-risk patients for early management in clinical practice.

\section{Methods}

\section{Patients}

The patients were included from four tertiary medical centers (the Second Affiliated Hospital of Zhejiang University
School of Medicine, Ruijin Hospital Affiliated to Shanghai Jiaotong University School of Medicine, Hangzhou First People's Hospital and Huzhou Central Hospital). For the derivation cohort, prospectively collected medical records of patients admitted from June 2018 to December 2018 were retrospectively investigated, and as a result a total of 250 cases were included. The data acquired from the derivation cohort was used to decide the sample size of the validation cohort with events per variable (EPV) method as reported previously [9]. Based on the analysis of the derivation cohort, the incidence of CCS was 55.2\%, and after univariate and multivariate analysis, seven variables entered the predictive model. Therefore, according to the EPV method and considering 15\% cases for incomplete data, sample size of the validation cohort was determined as: $N=7 \times 10 \div 0.552 \times 1.15=146$. Eventually, 160 patients consecutively admitted between January 2019 and April 2019 were enrolled prospectively to formed the validation cohort.

Patients were included if aged $\geq 18$ years old and diagnosed with acute stroke within 7 days of symptom onset. The diagnosis of stroke was based on persistent neurological deficits and confirmation by computed tomography $(\mathrm{CT})$ and/or magnetic resonance imaging (MRI).

Exclusion criteria were as follows: (1) CT showed intracranial hemorrhage or subarachnoid hemorrhage; (2) incomplete data for myocardial zymogram, echocardiograph, and/or electrocardiogram (ECG) data within $48 \mathrm{~h}$ after admission; (3) history of cardiac disease before admission; (4) cardioembolic stroke subtype; (5) concurrent malignant neoplasm, severe liver, kidney or cardiopulmonary disorder.

\section{Diagnostic criteria of CCS}

CCS was diagnosed according to the following criteria [10]: (1) no previous history of heart disease; (2) clear diagnosis of acute ischemic stroke; (3) any secondary cardiac damage manifestations. The manifestation includes: (1) ECG changes, including ST segment elevation or depression, $\mathrm{T}$ wave changes and QT prolongation [11-13]; (2) cardiac dysfunctions in echocardiography such as left ventricular diastolic dysfunction, [14] abnormal ventricular wall motion, [15] and decreased left ventricular ejection fraction [16]; (3) elevated peripheral cardiac markers by laboratory tests including troponin [17] and B-type natriuretic peptide [18].

\section{Statistical analysis}

Continuous data was expressed as mean \pm standard deviation (SD) and analyzed with $t$ test if normally distributed, otherwise the data was expressed by the median and interquartile ranges, and Mann-Whitney $U$ test was used. Categorical data was described by frequencies and percentage, and the $\chi^{2}$ test or Fisher's exact tests was used 
when appropriate. Univariate analysis was performed to detect potential association between CCS and the following variables respectively: age, sex, subtype of stroke, vital signs on admission (temperature and mean arterial pressure), Glasgow Coma Scale (GCS), National Institutes of Health Stroke Scale (NIHSS) Score, medical history (hypertension, diabetes, previous stroke, smoking and drinking), laboratory tests, including white blood cell count, neutrophil, prothrombin time (PT), activated partial thromboplastin time (APTT), fibrinogen, D-Dimer, glutamic-pyruvic transaminase, serum potassium, glucose, urea nitrogen, creatinine, triglycerides and low-density lipoprotein, and echocardiography findings (intima-media thickness, carotid stenosis, and left ventricular ejection fraction). Carotid stenosis was classified according to NASCET criteria: $<30 \%$ is classified as mild, $30-69 \%$ is moderate, and $>=70 \%$ is severe stenosis [19]. Data from the derivation cohort were entered into logistic regression to identify independent predictors and to develop the predictive model if the univariate analysis showed significant association $(P<0.05)$. The calibration were tested by Hosmer-Lemeshow (HL) goodness-of-fit test, and the discriminative ability was evaluated by $\mathrm{C}$ statistics in the derivation cohort and the validation cohort respectively. The rating scale was established with the magnitude of the logistic regression coefficient, and the cut-off valued was determined with receiver operating characteristic curve (ROC) curve. Statistical analysis was performed using SPSS 25.0 (IBM, Armonk, NY).

\section{Results}

Between June 2018 and December 2018, a total of 250 ischemic stroke patients were included as the derivation cohort (Fig. 1), and among them 138 cases of CCS occurred, with an prevalence of $55.2 \%$. Baseline characteristics was presented in Table 1. Univariate analysis showed that the following variables were significantly associated with the occurrence of CCS: age, sex, NIHSS, Neutrophil, PT, APTT, D-dimer, Carotid Stenosis and LVEF (Table 1). These variables were entered into multivariate logistic regression analysis, and seven independent predictors of CCS were identified: age, sex, NIHSS, Neutrophil, PT, APTT, Carotid Stenosis (Table 2). The HL test showed good calibration $(P=0.492)$. The discriminant validity of the model was evaluated by the area under the ROC curve (AUC), and finally $\mathrm{AUC}=0.888$, with sensitivity of 0.935 , specificity of 0.720 , and Youden index of 0.655 (Fig. 2. panel a).

The model was validated with the external validation cohort including patients admitted from January 2019 to April 2019 (Table 3). Among the 160 cases, 67 CCS actually occurred, whereas 93 cases were predicted by model (Table 4). The results showed that the CCS prediction probability of the model was in good agreement with the actual incidence, and the difference was not $\operatorname{significant}(P=$ 0.067 ). The AUC of this model was 0.813 , with the sensitivity of 0.642 , the specificity of 0.914 . (Fig. 2. panel b) The validation results showed the accuracy of $68.75 \%$. suggesting that the CCS risk prediction model established in this study has good discriminating ability.

Based on the logistic regression coefficients of the validated model, the PANSCAN scale was developed, with its items and corresponding scores presented in Table 5. The cut-off value was determined with ROC curve and Youden index. When Youden index reached the maximum, the cut-off value was 3 points. As a result, ischemic stroke patients with a PANSCAN score of 3 or more points were identified as high risk individuals.

\section{Discussion}

CCS is a common acute complication of acute stroke, especially within 3 days of stroke onset [20]. In this study, the incidence of CCS was $55.2 \%$. The cases included in this study were mainly from the Second Affiliated Hospital

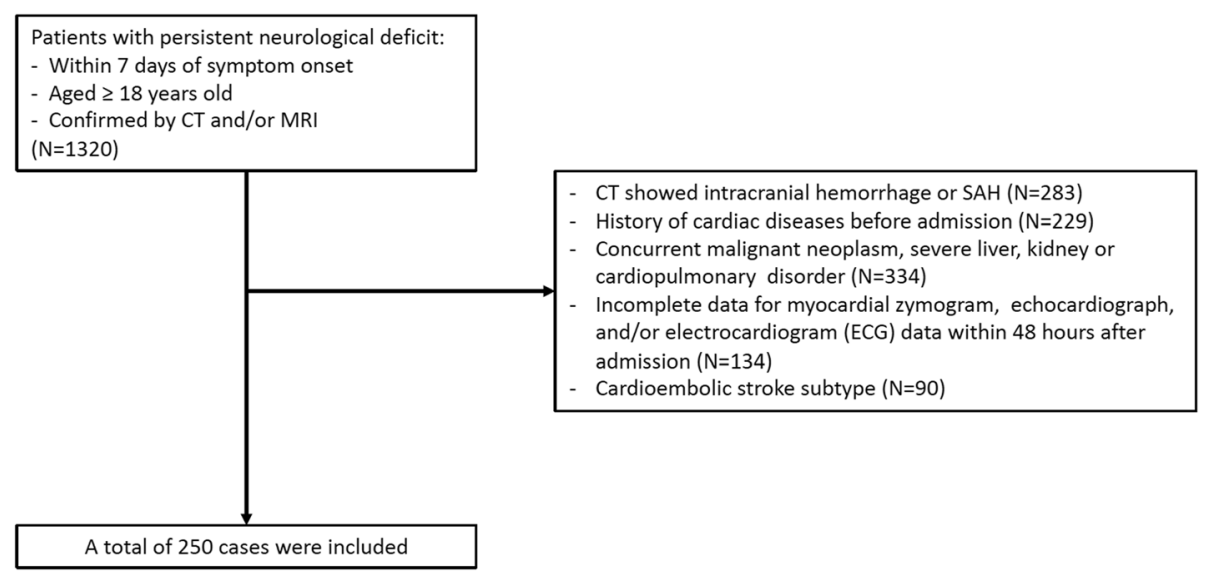

Fig. 1 Flow chart of patient inclusion 
Table 1 Baseline Characteristics of Patients in the Derivation Cohort $(n=250)$

\begin{tabular}{|c|c|c|c|c|}
\hline Characteristics & & no CCS, $n=112$ & $\mathrm{CCS}, n=138$ & $P$-value \\
\hline \multirow[t]{2}{*}{ Age, n (\%) } & $<65$ & $76(67.9)$ & $50(36.2)$ & $<0.001^{*}$ \\
\hline & $\geq 65$ & $36(32.1)$ & $88(63.8)$ & \\
\hline \multirow[t]{2}{*}{ Sex, n (\%) } & Male & $70(62.5)$ & $56(40.6)$ & $0.001^{*}$ \\
\hline & Female & $42(37.5)$ & $82(59.4)$ & \\
\hline \multirow[t]{2}{*}{ Stroke location, n (\%) } & Brain stem & $18(16.1)$ & $30(21.7)$ & 0.155 \\
\hline & Others & $94(83.9)$ & $98(71.0)$ & \\
\hline \multirow[t]{2}{*}{ Temperature $\left({ }^{\circ} \mathrm{C}\right), \mathrm{n}(\%)$} & $<37.5$ & $98(87.5)$ & $118(85.5)$ & 0.713 \\
\hline & $\geq 37.5$ & $14(12.5)$ & $20(14.5)$ & \\
\hline \multirow[t]{2}{*}{ Mean Arterial Pressure (mmHg), n (\%) } & Normal $(<105)$ & $44(39.3)$ & $60(43.5)$ & 0.521 \\
\hline & Elevated( $\geq 105)$ & $68(60.7)$ & $78(56.5)$ & \\
\hline \multirow[t]{4}{*}{ GCS Score, n (\%) } & Conscious(15) & $108(96.4)$ & $120(87.0)$ & $0.027^{*}$ \\
\hline & Mild(12 14) & $2(1.8)$ & $12(8.7)$ & \\
\hline & Moderate(9 11) & $0(0.0)$ & $4(2.9)$ & \\
\hline & Coma $(\leq 8)$ & $2(1.8)$ & $2(1.4)$ & \\
\hline \multirow[t]{3}{*}{ NIHSS Score, n (\%) } & 0 & $54(48.2)$ & $20(14.5)$ & $<0.001^{*}$ \\
\hline & $1 \sim 4$ & $44(39.3)$ & $60(43.5)$ & \\
\hline & $>4$ & $14(12.5)$ & $58(42.0)$ & \\
\hline \multirow[t]{2}{*}{ Hypertension, n (\%) } & No & $32(28.6)$ & $58(42.0)$ & 0.34 \\
\hline & Yes & $80(71.4)$ & $80(58.0)$ & \\
\hline \multirow[t]{2}{*}{ Diabetes, n (\%) } & No & $82(74.5)$ & $96(70.6)$ & 0.567 \\
\hline & Yes & $28(25.5)$ & $40(29.4)$ & \\
\hline \multirow[t]{2}{*}{ Stroke Times, n (\%) } & 1 times & $96(85.7)$ & $110(79.7)$ & 0.245 \\
\hline & $>1$ times & $16(14.3)$ & $28(20.3)$ & \\
\hline \multirow[t]{2}{*}{ Smoking history, n (\%) } & No & $104(92.9)$ & $122(88.4)$ & 0.284 \\
\hline & Yes & $8(7.1)$ & $16(11.6)$ & \\
\hline \multirow[t]{2}{*}{ Drinking history, n (\%) } & No & $72(64.3)$ & $98(71.0)$ & 0.277 \\
\hline & Yes & $40(35.7)$ & $40(29.0)$ & \\
\hline \multicolumn{2}{|l|}{ WBC(10^9/L), median (IQR) } & $6.30(5.60,8.18)$ & $6.75(5.43,8.90)$ & 0.497 \\
\hline \multicolumn{2}{|l|}{ Neutrophil(\%), median (IQR) } & $61.3(56.1,66.1)$ & $66.0(59.6,76.0)$ & $<0.01^{*}$ \\
\hline \multicolumn{2}{|l|}{ PT(s), median (IQR) } & $13.0(12.3,13.9)$ & $13.6(12.8,15.1)$ & $0.012^{*}$ \\
\hline \multicolumn{2}{|l|}{ APTT(s), median (IQR) } & $36.6(34.4,38.3)$ & $37.2(34.4,42.0)$ & $0.031^{*}$ \\
\hline \multicolumn{2}{|l|}{ Fibrinogen(g/L), median (IQR) } & $3.29(2.80,3.83)$ & $2.96(2.51,3.80)$ & $0.022^{*}$ \\
\hline \multicolumn{2}{|l|}{ D-Dimer $(<500$ g/l FEU), median (IQR) } & $390.0(300.0,630.0)$ & $490.0(300.0,1130.0)$ & $0.023^{*}$ \\
\hline \multicolumn{2}{|l|}{ GPT(U/L), median (IQR) } & $18.0(13.0,29.0)$ & $17.0(13.0,27.0)$ & 0.609 \\
\hline \multicolumn{2}{|l|}{ GOT(U/L), median (IQR) } & $22.0(19.0,27 . .8)$ & $23.0(18.0,28.5)$ & 0.813 \\
\hline \multicolumn{2}{|l|}{ Serum Potassium, median (mmol/l)(IQR) } & $3.72(3.48,3.89)$ & $3.79(3.37,3.95)$ & 0.997 \\
\hline \multicolumn{2}{|l|}{ Blood Glucose, median (mmol/l) (IQR) } & $5.22(4.75,6.41)$ & $5.21(4.66,7.27)$ & 0.760 \\
\hline \multicolumn{2}{|l|}{ BUN (mmol/l), median (IQR) } & $4.59(3.67,5.61)$ & $5.00(4.15,6.14)$ & $0.037^{*}$ \\
\hline \multicolumn{2}{|l|}{ Serum creatinine $(\mathrm{mmol} / \mathrm{l})$,median $(\mathrm{QQR})$} & $58.0(49.3,70.8)$ & $59.0(47.8,71.5)$ & 0.784 \\
\hline Triglycerides (mmol/l), median (IQR) & & $1.31(0.98,1.69)$ & $1.20(0.87,1.57)$ & 0.098 \\
\hline LDL (mmol/l), median (IQR) & & $2.28(1.77,2.97)$ & $2.10(1.48,2.55)$ & 0.010 \\
\hline IMT, n (\%) & Normal & $35(34.7)$ & $42(34.1)$ & 0.483 \\
\hline & Thicken & $66(65.3)$ & $81(65.9)$ & \\
\hline Carotid Stenosis, n (\%) & Normal & $56(55.4)$ & $42(33.6)$ & $<0.001^{*}$ \\
\hline
\end{tabular}


Table 1 Baseline Characteristics of Patients in the Derivation Cohort $(n=250)$ (Continued)

\begin{tabular}{|c|c|c|c|c|}
\hline Characteristics & & no CCS, $n=112$ & CCS, $n=138$ & $P$-value \\
\hline & Mild & $36(35.7)$ & $47(37.6)$ & \\
\hline & Moderate to Severe & $9(8.9)$ & $36(28.8)$ & \\
\hline \multirow[t]{4}{*}{ LVEF(\%), n (\%) } & $<50$ & $2(2.2)$ & $6(5.0)$ & $0.014^{*}$ \\
\hline & $50 \sim 55$ & $0(0.0)$ & $3(2.5)$ & \\
\hline & $55 \sim 60$ & $14(15.1)$ & $27(22.3)$ & \\
\hline & $\geq 60$ & 77 (82.8) & $85(70.2)$ & \\
\hline
\end{tabular}

indicated $P<0.05$

Abbreviations: GCS Glasgow coma scale, NIHSS National Institutes of Health Stroke Scale, WBC White blood cell, GPT Glutamic Pyruvic Transaminase, GOT GlutamicOxalacetic Transaminease, BUN Blood Urea Nitrogen, LDL Low Density Lipoprotein, IMT Intima-Media Thickness, LVEF Left Ventricular Ejection Fraction, IQR interquartile range, FEU Fibrinogen Equivalent Units

of Zhejiang University School of Medicine, Ruijin Hospital affiliated to Shanghai Jiaotong University School of Medicine, Hangzhou First People's Hospital and Huzhou Central Hospital. The data were complete and credible. Although the current study was not extended to the prognosis or mortality, previous studies demonstrated that the development of CCS subsequent to stroke resulted in significant increase in hospitalization costs and prolonged hospital stay, [21] and severe cases can lead to worsened functional outcome and even death [3, 22]. Therefore, early identification and prevention of CCS were important in stroke patients.

In this study, we proved that that age, sex, NIHSS score, neutrophil, PT, APTT, and carotid stenosis were independent risk factors for CCS in stroke patients. Most of these findings were consistent with previous studies: higher age, female and coagulation were well- established risk factors for cardiac and cardiovascular events [6]. In addition, we found that carotid stenosis was also identified as an independent predictor for CCS. This finding is consistent with the previous publication by Gaia Sirimarco, which demonstrated that the presence of carotid stenosis is independently associated with increased risk of future coronary artery events and is a marker of disease severity [23]. Theoretically, carotid stenosis indicates the overall atherosclerosis level of vascular and can therefore suggest potential cardiovascular risk [24]. Pathological changes of carotid artery are widely adopted as surrogate for predictive risk factors for cardiovascular disease, [25] although evidence was conflicting. Previous studies demonstrated that intimal medial thickness and plaque prevalence are correlated with increased risk of cardiovascular disease, [26, 27] whereas recent study found that carotid plaque length

Table 2 Logistic multivariate regression analysis of CCS $(n=250)$

\begin{tabular}{|c|c|c|c|c|c|c|c|}
\hline Items & Category & Regression Coefficient & SD & Wald & $P$-value & $O R$ & $95 \% \mathrm{Cl}$ \\
\hline \multirow[t]{2}{*}{ Age } & $<65$ & Reference & 0.368 & 6.993 & 0.008 & 2.646 & $(1.286,5.442)$ \\
\hline & $\geq 65$ & 0.973 & & & & & \\
\hline \multirow[t]{2}{*}{ Sex } & Male & Reference & 0.367 & 5.577 & 0.018 & 2.38 & $(1.159,4.886)$ \\
\hline & Female & 0.867 & & & & & \\
\hline \multirow[t]{3}{*}{ NIHSS Score } & 0 & Reference & & 28.127 & & & \\
\hline & 1 to 4 & 1.546 & 0.463 & 11.133 & 0.001 & 4.692 & $(1.892,11.633)$ \\
\hline & $\geq 5$ & 2.76 & 0.521 & 28.031 & $<0.01$ & 15.797 & $(5.687,43.881)$ \\
\hline \multirow[t]{2}{*}{ Neutrophil } & Normal (50-70\%) & Reference & 0.393 & 8.231 & 0.004 & 3.089 & $(1.429,6.673)$ \\
\hline & $<50 \%$ OR $\geq 70 \%$ & 1.128 & & & & & \\
\hline \multirow[t]{2}{*}{ PT } & $<14 \mathrm{~s}$ & Reference & 0.368 & 8.442 & 0.004 & 2.915 & $(1.416,5.998)$ \\
\hline & $\geq 14 \mathrm{~s}$ & 1.07 & & & & & \\
\hline \multirow[t]{2}{*}{ APTT } & $<45 \mathrm{~s}$ & Reference & 0.45 & 10.594 & 0.001 & 4.33 & $(1.791,10.465)$ \\
\hline & $\geq 45 \mathrm{~s}$ & 1.466 & & & & & \\
\hline \multirow[t]{3}{*}{ Carotid Stenosis } & Normal & Reference & & 9.451 & & & \\
\hline & Mild & 0.423 & 0.404 & 1.095 & 0.295 & 1.527 & $(0.691,3.373)$ \\
\hline & Moderate to Severe & 1.69 & 0.55 & 9.438 & 0.002 & 5.417 & $(1.843,15.919)$ \\
\hline
\end{tabular}



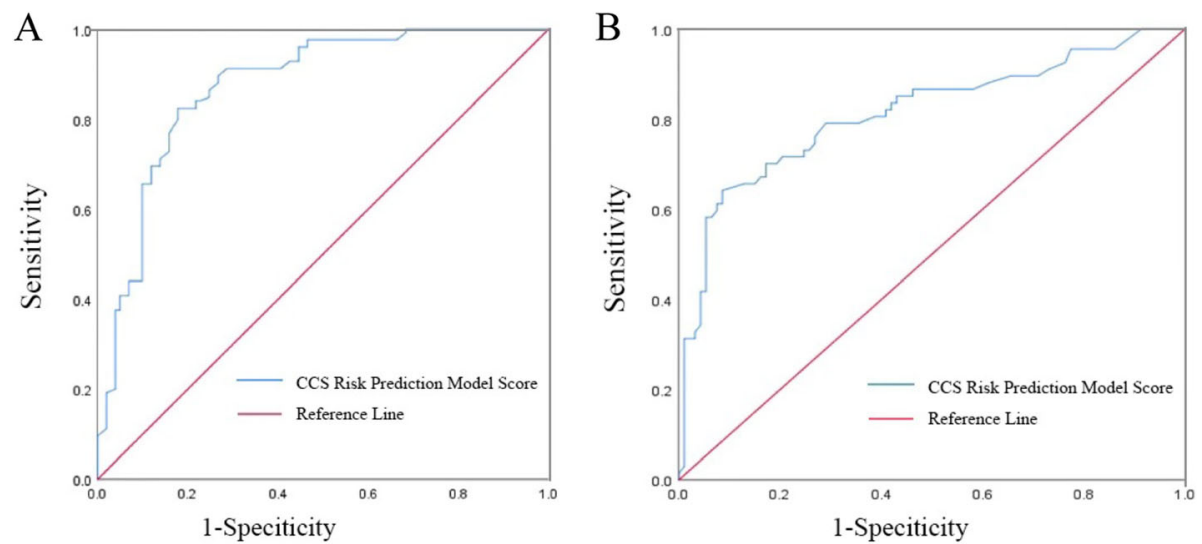

Fig. 2 ROC curves of derivation cohort (Panel a) and validation cohort (Panel b)

Table 3 Comparison of Risk Factors between Derivation and Validation Groups

\begin{tabular}{|c|c|c|c|}
\hline & Derivation Group & Validation Group & $P$ \\
\hline$n$ & 250 & 160 & \\
\hline \multicolumn{4}{|l|}{ Age, n (\%) } \\
\hline$<65$ & $126(50.4 \%)$ & 95 (59.4\%) & \multirow[t]{2}{*}{0.085} \\
\hline$\geq 65$ & $124(49.6 \%)$ & $65(40.6 \%)$ & \\
\hline \multicolumn{4}{|l|}{ Sex, n (\%) } \\
\hline Male & $126(50.4 \%)$ & $83(51.9 \%)$ & \multirow[t]{2}{*}{0.840} \\
\hline Female & $124(49.6 \%)$ & $77(48.1 \%)$ & \\
\hline \multicolumn{4}{|l|}{ NIHSS Score, n (\%) } \\
\hline 0 & $74(29.6 \%)$ & $60(37.5 \%)$ & \multirow[t]{3}{*}{0.070} \\
\hline $1 \sim 4$ & $104(41.6 \%)$ & 49 (30.6\%) & \\
\hline$>4$ & $72(28.8 \%)$ & 51 (31.9\%) & \\
\hline \multicolumn{4}{|c|}{ Neutrophi(\%), median (IQR) } \\
\hline & $150(60 \%)$ & $93(58.1 \%)$ & \multirow[t]{2}{*}{0.757} \\
\hline & $100(40 \%)$ & 67 (41.9\%) & \\
\hline \multicolumn{4}{|l|}{ PT(s), median (IQR) } \\
\hline & $136(54.4 \%)$ & $89(55.6 \%)$ & \multirow[t]{2}{*}{0.839} \\
\hline & $114(45.6 \%)$ & $71(44.4 \%)$ & \\
\hline \multicolumn{4}{|l|}{ APTT(s), median (IQR) } \\
\hline & $198(79.2 \%)$ & 115 (71.9\%) & \multirow[t]{2}{*}{0.096} \\
\hline & $52(20.8 \%)$ & $45(28.1 \%)$ & \\
\hline \multicolumn{4}{|l|}{ Carotid Stenosis, n (\%) } \\
\hline Normal & $98(43.4 \%)$ & 79 (49.4\%) & \multirow[t]{3}{*}{0.503} \\
\hline Mild & $83(36.7 \%)$ & $52(32.5 \%)$ & \\
\hline Moderate to Severe & 45 (19.9\%) & $29(18.1 \%)$ & \\
\hline
\end{tabular}

can be a better predictor [28]. In our study, we found carotid stenosis was independently associated with CCS, which can be explained by the hypothesis that carotid stenosis represents long term accumulative exposure of cardiovascular risk factors [29].

Furthermore, we found that higher NIHSS score and elevated neutrophil counts also added to the risk for CCS. One possible explanation is the catecholamine surge hypothesis, the most widely accepted theory for the development of CCS [3]. According to the hypothesis, sudden and severe cerebral attack causes abnormal activation of autonomic nervous system that leads to catecholamine surge and results in cardiac dysfunction [3]. In support of this hypothesis, previous investigators showed that increased stroke severity was related to impaired cardiac autonomic modulation, [30] and was associated with higher cardiac mortality after stroke [31]. Consistently, our study identified that NIHSS, a direct index of stroke severity, was an independent predictor of CCS. Similarly, neutrophil is also a marker of stroke severity, [32] and is related to increased risk of new cardiovascular events, [33] as previous studies demonstrated.

This study included a large multicenter sample of Chinese population for analysis. Based on the results of univariate analysis and logistic multi-factor regression analysis in the derivation cohort and verification in the validation cohort, a risk prediction scale of CCS was

Table 4 Model Validation $(n=160)$

\begin{tabular}{llll}
\hline Model & \multicolumn{2}{l}{ CCS actually occurred } & Total \\
\cline { 2 - 3 } prediction & No & Yes & \\
\hline No & 63 & 16 & 79 \\
Yes & 30 & 51 & 81 \\
Total & 93 & 67 & 160 \\
\hline
\end{tabular}

Kappa value $=0.426$ $p<0.001$ 
Table 5 The PANSCAN Scale

\begin{tabular}{lll}
\hline Items & Category & Points \\
\hline Age & $<65$ & 0 \\
& $\geq 65$ & 1 \\
Sex & Male & 0 \\
& Female & 1 \\
NIHSS Score & 0 & 0 \\
& 1 to 4 & 2 \\
Neutrophil & $\geq 5$ & 3 \\
& Normal (50-70\%) & 0 \\
PT & $<50 \%$ OR $\geq 70 \%$ & 1 \\
& $<14 \mathrm{~s}$ & 0 \\
APTT & $\geq 14 \mathrm{~s}$ & 1 \\
& $<45 \mathrm{~s}$ & 0 \\
Carotid Stenosis & $\geq 45 \mathrm{~s}$ & 1 \\
& Normal & 0 \\
& Mild & 0 \\
\hline
\end{tabular}

established. It is suitable for the Chinese population to predict the occurrence of CCS. The model can be further promoted in clinical practice. The predictive model can contribute to clinical assessments for CCS risk, as well as health education, lifestyle interventions, and to improve patient compliance and satisfaction.

The major limitation is that based on the design of our study, patients with previous medical history of cardiac disorder and cardio-embolic stroke subtype was not included. However, in this population, attention on cardiac problems was routinely given at the first place, so the aim of the study is to stratify high-risk population without previous known heart diseases, among whom attention on cardiac conditions is often neglected. Another flaw is that we defined pre-admission history of cardiac disorder according to medical history of patients. Optimally, baseline cardiac evaluations should be accomplished immediately after stroke onset to exclude previous cardiac problems, but it is difficult to achieve in real world practice, and in our study, we included patients within 7 days after stoke. In this case, we reviewed patients' past medical history and previous medical record as baseline cardiac conditions to minimize potential bias. Finally, our study only included Chinese population, so the generalization of our finding to other races and ethnicities was not validated in our study. Studies including larger sample size and other races and ethnicities are needed for further validation and generalization of the scale.

The PANSCAN scale established in this study is simple and feasible for clinical reference. In the future studies, prediction software can be developed to achieve intelligent and accurate warning of CCS, which will provide a reliable reference for clinical decision-making, and bring great convenience. Therefore, the results of this study have a good application value and prospects.

\section{Conclusion}

This study used logistic regression analysis to screen the risk factors affecting the incidence of CCS, and to construct a scientific and effective risk prediction scale. This provides a practical method for objectively quantifying the risk of developing CCS in stroke patients. The scale shows practical clinical significance and convenience to prevent the occurrence of CCS and to improve the clinical prognosis of stroke。

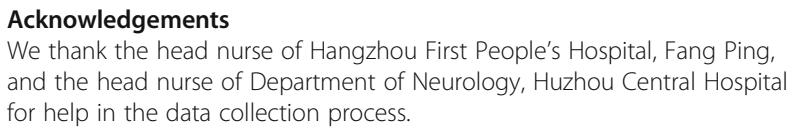

$L H, X X, S X, C J, M D, Z Y$ collected clinical data. LH and XX were major contributor in writing the manuscript. YM was responsible for statistical analysis of the data. All authors have read and approved the manuscript.

\section{Funding}

This study was financially supported by the Scientific Research Fund Project of Zhejiang Health Commission (2017KY069), Shanghai Sailing program (19YF1430100) and the Natural Science Foundation of China (81901180). The funding body did not participate in the design of the study, the collection, analysis, and interpretation of data, and in writing the manuscript.

\section{Availability of data and materials}

The datasets used and/or analyzed during the current study are available from the corresponding author on reasonable request.

\section{Ethics approval and consent to participate}

The study was approved by ethic committee of the Second Affiliated Hospital of Zhejiang University School of Medicine, Ruijin Hospital affiliated to Shanghai Jiaotong University School of Medicine, Hangzhou First People's Hospital and Huzhou Central Hospital. Written consent was waived by ethic committee in each center, as the study collected data from reviewing medical records of standard care.

\section{Consent for publication}

Not applicable.

\section{Competing interests}

The authors declare that they have no competing interests.

\section{Author details}

${ }^{1}$ Hangzhou Medical College, Hangzhou 310053, China. ${ }^{2}$ The Second Affiliated Hospital, School of Medicine, Zhejiang University, 88 Jiefang Road, Hangzhou 310009, China. ${ }^{3}$ Medicine \& Nursing Science School, Huzhou University, 1 Xueshi Road, Huzhou 313000, China. ${ }^{4}$ Ruijin Hospital, Shanghai Jiaotong University School of Medicine, 197 Ruijin Second Road, Shanghai 200025, China.

Received: 21 January 2020 Accepted: 18 June 2020

Published online: 08 July 2020

References

1. Byer E, Ashman R, Toth LA. Electrocardiograms with large, upright T waves and long Q-T intervals. Am Heart J. 1947;33(6):796-806. https://doi.org/10. 1016/0002-8703(47)90025-2. 
2. Burch GE, Meyers R, Abildskov JA. A new electrocardiographic pattern observed in cerebrovascular accidents. Circulation. 1954;9(5):719-23. https:// doi.org/10.1161/01.cir.9.5.719.

3. Chen Z, Venkat $P$, Seyfried D, Chopp M, Yan T, Chen J. Brain-heart interaction: cardiac complications after stroke. Circ Res. 2017;121(4):451-68 https://doi.org/10.1161/CIRCRESAHA.117.311170.

4. Samuels MA. The brain-heart connection. Circulation. 2007;116(1):77-84. https://doi.org/10.1161/CIRCULATIONAHA.106.678995.

5. Norris JW, Froggatt GM, Hachinski VC. Cardiac arrhythmias in acute stroke. Stroke. 1978;9(4):392-6. https://doi.org/10.1161/01.str.9.4.392.

6. Kallmunzer B, Breuer L, Kahl N, Bobinger T, Raaz-Schrauder D, Huttner HB, et al. Serious cardiac arrhythmias after stroke: incidence, time course, and predictors--a systematic, prospective analysis. Stroke. 2012;43(11):2892-7. https://doi.org/10.1161/STROKEAHA.112.664318.

7. Cushman M, Judd SE, Howard VJ, Kissela B, Gutierrez OM, Jenny NS, et al. Nterminal pro-B-type natriuretic peptide and stroke risk: the reasons for geographic and racial differences in stroke cohort. Stroke. 2014;45(6):164650. https://doi.org/10.1161/STROKEAHA.114.004712.

8. Yeo LLL, Andersson T, Yee KW, Tan BYQ, Paliwal P, Gopinathan A, et al. Synchronous cardiocerebral infarction in the era of endovascular therapy: which to treat first? J Thromb Thrombolysis. 2017:44(1):104-11. https://doi. org/10.1007/s11239-017-1484-2

9. Sardar Sinha M, Ansell-Schultz A, Civitelli L, Hildesjo C, Larsson M, Lannfelt L, et al. Alzheimer's disease pathology propagation by exosomes containing toxic amyloid-beta oligomers. Acta Neuropathol. 2018;136(1):41-56. https:// doi.org/10.1007/s00401-018-1868-1.

10. Mierzewska-Schmidt M, Gawecka A. Neurogenic stunned myocardium - do we consider this diagnosis in patients with acute central nervous system injury and acute heart failure? Anaesthesiol Intensive Ther. 2015;47(2):17580. https://doi.org/10.5603/AIT.2015.0017.

11. Danese A, Cappellari M, Pancheri E, Mugnai G, Micheletti N, Tomelleri G, et al. The dispersion of myocardial repolarization in ischemic stroke and intracranial hemorrhage. J Electrocardiol. 2018;51(4):691-5. https://doi.org/ 10.1016/j.jelectrocard.2018.05.007.

12. Hayiroglu MI, Turkkan C, Bozbeyoglu E. How can we answer more questions about the association between myocardial repolarization parameters and stroke? J Electrocardiol. 2018;51(6):1153. https://doi.org/10.1016/j. jelectrocard.2018.08.012.

13. Stone J, Mor-Avi V, Ardelt A, Lang RM. Frequency of inverted electrocardiographic T waves (cerebral T waves) in patients with acute strokes and their relation to left Ventricular Wall motion abnormalities. Am J Cardiol. 2018;121(1):120-4. https://doi.org/10.1016/j.amjcard.2017.09.025.

14. Park HK, Kim BJ, Yoon CH, Yang MH, Han MK, Bae HJ. Left ventricular diastolic dysfunction in ischemic stroke: functional and vascular outcomes. J Stroke. 2016;18(2):195-202. https://doi.org/10.5853/jos.2015.01697.

15. van der Bilt I, Hasan D, van den Brink R, Cramer MJ, van der Jagt M, van Kooten $\mathrm{F}$, et al. Cardiac dysfunction after aneurysmal subarachnoid hemorrhage: relationship with outcome. Neurology. 2014;82(4):351-8. https://doi.org/10.1212/WNL.0000000000000057.

16. Yoshimura S, Toyoda K, Ohara T, Nagasawa H, Ohtani N, Kuwashiro T, et al. Takotsubo cardiomyopathy in acute ischemic stroke. Ann Neurol. 2008;64(5): 547-54. https://doi.org/10.1002/ana.21459.

17. Kerr G, Ray G, Wu O, Stott DJ, Langhorne P. Elevated troponin after stroke: a systematic review. Cerebrovasc Dis. 2009;28(3):220-6. https://doi.org/10. $1159 / 000226773$.

18. Garcia-Berrocoso T, Giralt D, Bustamante A, Etgen T, Jensen JK, Sharma JC, et al. B-type natriuretic peptides and mortality after stroke: a systematic review and meta-analysis. Neurology. 2013;81(23):1976-85. https://doi.org/ 10.1212/01.wnl.0000436937.32410.32.

19. North American Symptomatic Carotid Endarterectomy Trial C, HJM B, Taylor DW, Haynes RB, Sackett DL, Peerless SJ, et al. Beneficial effect of carotid endarterectomy in symptomatic patients with high-grade carotid stenosis. N Engl J Med. 1991;325(7):445-53. https://doi.org/10.1056/ NEJM199108153250701.

20. Ripoll JG, Blackshear JL, Diaz-Gomez JL. Acute cardiac complications in critical brain disease. Neurosurg Clin N Am. 2018;29(2):281-97. https://doi. org/10.1016/j.nec.2017.11.007.

21. Yousef KM, Crago E, Lagattuta TF, Hravnak M. Clinical presentation to the emergency department predicts subarachnoid hemorrhage-associated myocardial injury. J Emerg Nurs. 2018;44(2):132-8. https://doi.org/10.1016/j. jen.2017.06.005.
22. Ripoll JG, Blackshear JL, Diaz-Gomez JL. Acute cardiac complications in critical brain disease. Neurol Clin. 2017;35(4):761-83. https://doi.org/10.1016/ j.ncl.2017.06.011.

23. Sirimarco G, Amarenco P, Labreuche J, Touboul PJ, Alberts M, Goto S, et al. Carotid atherosclerosis and risk of subsequent coronary event in outpatients with atherothrombosis. Stroke. 2013;44(2):373-9. https://doi.org/10.1161/ STROKEAHA.112.673129.

24. Wang D, Wang J, Jin C, Ji R, Wang A, Li X, et al. Asymptomatic Extracranial artery stenosis and the risk of cardiovascular and cerebrovascular diseases. Sci Rep. 2016;6:33960. https://doi.org/10.1038/srep33960.

25. Finn AV, Kolodgie FD, Virmani R. Correlation between carotid intimal/media thickness and atherosclerosis: a point of view from pathology. Arterioscler Thromb Vasc Biol. 2010;30(2):177-81. https://doi.org/10.1161/ATVBAHA.108. 173609

26. O'Leary DH, Polak JF, Kronmal RA, Manolio TA, Burke GL, Wolfson SK Jr. Carotid-artery intima and media thickness as a risk factor for myocardial infarction and stroke in older adults. Cardiovascular Health Study Collaborative Research Group. N Engl J Med. 1999;340(1):14-22. https://doi. org/10.1056/NEJM199901073400103.

27. Jeevarethinam A, Venuraju S, Weymouth M, Atwal S, Lahiri A. Carotid intimal thickness and plaque predict prevalence and severity of coronary atherosclerosis: a pilot study. Angiology. 2015;66(1):65-9. https://doi.org/10. 1177/0003319714522849

28. Tang W, Shen X, Li H, Bai Y, Zhang B, Guo Z, et al. The independent and incremental value of ultrasound carotid plaque length to predict the presence and severity of coronary artery disease: analysis from the carotid plaque length prospective registry. Eur Heart J Cardiovasc Imaging. 2019. https://doi.org/10.1093/ehjci/jez304.

29. Wilson PW, Hoeg JM, D'Agostino RB, Silbershatz H, Belanger AM, Poehlmann $\mathrm{H}$, et al. Cumulative effects of high cholesterol levels, high blood pressure, and cigarette smoking on carotid stenosis. N Engl J Med. 1997;337(8):516-22. https://doi.org/10.1056/NEJM199708213370802.

30. Hilz MJ, Moeller S, Akhundova A, Marthol H, Pauli E, De Fina P, et al. High NIHSS values predict impairment of cardiovascular autonomic control. Stroke. 2011;42(6):1528-33. https://doi.org/10.1161/STROKEAHA.110.607721.

31. Prosser J, MacGregor L, Lees KR, Diener HC, Hacke W, Davis S, et al. Predictors of early cardiac morbidity and mortality after ischemic stroke. Stroke. 2007;38(8):2295-302. https://doi.org/10.1161/STROKEAHA.106.471813.

32. Xue J, Huang W, Chen X, Li Q, Cai Z, Yu T, et al. Neutrophil-to-lymphocyte ratio is a prognostic marker in acute ischemic stroke. J Stroke Cerebrovasc Dis. 2017;26(3):650-7. https://doi.org/10.1016/j.jstrokecerebrovasdis.2016.11. 010.

33. Zhu B, Pan $Y$, Jing J, Meng $X$, Zhao X, Liu L, et al. Neutrophil counts, neutrophil ratio, and new stroke in minor ischemic stroke or TIA. Neurology. 2018;90(21):e1870-e8. https://doi.org/10.1212/WNL.0000000000005554.

\section{Publisher's Note}

Springer Nature remains neutral with regard to jurisdictional claims in published maps and institutional affiliations.

Ready to submit your research? Choose BMC and benefit from:

- fast, convenient online submission

- thorough peer review by experienced researchers in your field

- rapid publication on acceptance

- support for research data, including large and complex data types

- gold Open Access which fosters wider collaboration and increased citations

- maximum visibility for your research: over $100 \mathrm{M}$ website views per year

At BMC, research is always in progress.

Learn more biomedcentral.com/submissions 